\title{
Lateral-bilateral Costal Branch (R. Costalis Lateralis): A Clinically Relevant Anatomical Variation
}

\author{
Rama Costal Lateral Bilateral (R. Costalis Lateralis): \\ Una Variación Anatómica Clínicamente Relevante
}

Emilio Farfán C.; Oscar Inzunza H. \& Mark Echeverría M.

FARFÁN, C. E.; INZUNZA, H. O. \& ECHEVERRÍA, M. M. Lateral-bilateral costal branch (r. costalis lateralis): a clinically relevant anatomical variation. Int. J. Morphol., 35(4):1512-1516, 2017.

SUMMARY: The lateral costal branch (LCB) is a variation present in 15-30\% of the population. This blood vessel runs parallel and laterally to the internal thoracic artery from which it originates. Knowledge about the LCB is relevant for thoracic surgeons. In this study we present the findings from the dissection in a practical teaching exercise of the cadaver of a 62-year-old male. The thoracic contents were accessed by raising the anterolateral thoracic wall, the pulmonary pedicles were dissected and both lungs were removed. We observed bilaterally the trajectory of the LCB at the level of the medial axillary line parallel to the internal thoracic artery. On the right side, the LCB originates from the internal thoracic artery at the level of the first rib and extends to the eighth intercostal space, with a length of $26 \mathrm{~cm}$ and a caliber of $1.95 \mathrm{~mm}$, communicating with the anterior and posterior intercostal arteries. The left branch originates from the internal thoracic close to their origin artery and extends until the sixth intercostal space, with a length of $14 \mathrm{~cm}$ and a caliber of $1.55 \mathrm{~mm}$. it connects with the anterior and posterior intercostal arteries. On both sides the arteries were accompanied by a pair of satellite veins. The lateral costal arteries form part of the circulation of the thoracic wall, constituting an accessory arterial system with a trajectory parallel to the internal thorax and the aorta. Knowledge of it is relevant for invasive procedures, and myocardial revascularization procedure.

KEY WORDS: Lateral costal branch; Anatomical variation; Clinical anatomy.

\section{INTRODUCTION}

The internal thoracic artery has received special attention in recent decades owing to the extensive use of myocardial revascularization in surgical procedure. With life expectancies rising, cardiac surgeons are presented with new challenges in attending an aging population. Coronary arterial bypass is today one of the most commonly performed surgeries, with around 800,000 procedures worldwide per year (Maddock et al., 2013).

Bypass surgery using the internal thoracic artery as a conduit has had better short, medium and long-term results than the use of the saphenous vein (Green et al., 1970; Cameron et al., 1995). At 10 years after coronary arterial bypass surgery, 90-95\% of internal thoracic bypasses are permeable and free from disease, while $75 \%$ of vein conduits are blocked or patients are severely ill (Fitzgibbon et al., 1996). The use of the left internal thoracic artery is widely considered the gold standard (Maddock et al.), and its success has even encouraged the use of both internal thoracic arteries, with excellent long-term results, although this implies a technically more challenging procedure (Lytle et al., 2004; Popovic et al., 2013). A recent study found improved longterm survival rates when multiple arterial conduits are used for bypass surgery instead of including vein-based conduits or the exclusive use of the left internal thoracic artery (Locker et al., 2012).

Based on a case report, this article seeks to provide a detailed anatomical description of the lateral-bilateral costal branch that can contribute to a better understanding of its presentation.

\section{MATERIAL AND METHOD}

Routine dissection of a male cadaver, age 62 , in a practical teaching activity in the Department of Anatomy. 
The thoracic content was accessed by bilateral costotomy. The anterolateral thoracic wall was lifted, the mediastinal parietal pleural and the fibrous pericardium had been removed, both pulmonary pedicles were sectioned and the lungs were removed.

In the inner lateral thoracic wall the bilaterally trajectory of a vascular package at the level of the medial axillary line was observed, parallel to the internal thoracic artery and originating from these vessel. This variation was later identified as the lateral costal branch as described in the literature.

The vessels were dissected to study their vascular territory. This procedure began by removing the parietal pleura, exposing both arteries from their origin to their termination. It was then possible to count the intercostal spaces that cover each vascular package. The endothoracic fascia was then removed and the lateral costal arteries and accompanying veins were exposed. To observe the anastomosis with the intercostal vessels it was necessary to remove the Innermost intercostal muscle.

Finally, the length and caliber of the lateral costal vessels were measured respectively with an electronic meter. We counted the number of anastomosis with intercostal vessels and registered the way in which they were established

\section{RESULTS}

Right lateral costal branch. The right lateral costal branch originates from the internal thoracic artery two $\mathrm{cm}$ from where the latter begins in the plane of the endothoracic fascia, deep in relation to intercostal VAN close the intercostal lymph node (Fig. 2). From its origin, the artery makes a descending and oblique trajectory in the thoracic wall at the level of the medial axillary line, extending to the eighth intercostal space (Fig. 1). In this path, the lateral costal branch establishes anastomosis with the posterior and anterior intercostal arteries of the first to eighth intercostal spaces through two fine branches, generating an intermediate longitudinal vascular axis for these arteries, as well as emitting direct branches for the thoracic wall, forming part of the arterial circuit of this wall. The lateral costal branch ends in anastomose with the posterior intercostal arteries of the eighth space. It is $26 \mathrm{~cm}$ long and has a caliber of 1.95 $\mathrm{mm}$ at its origin in the internal thoracic artery. In its trajectory, the artery is accompanied by two satellite veins that together establish horizontal anastomosis between them as a bridge, which are connected behind the artery. Venous anastomosis is observed in each intercostal space (Fig. 2). Caudally the

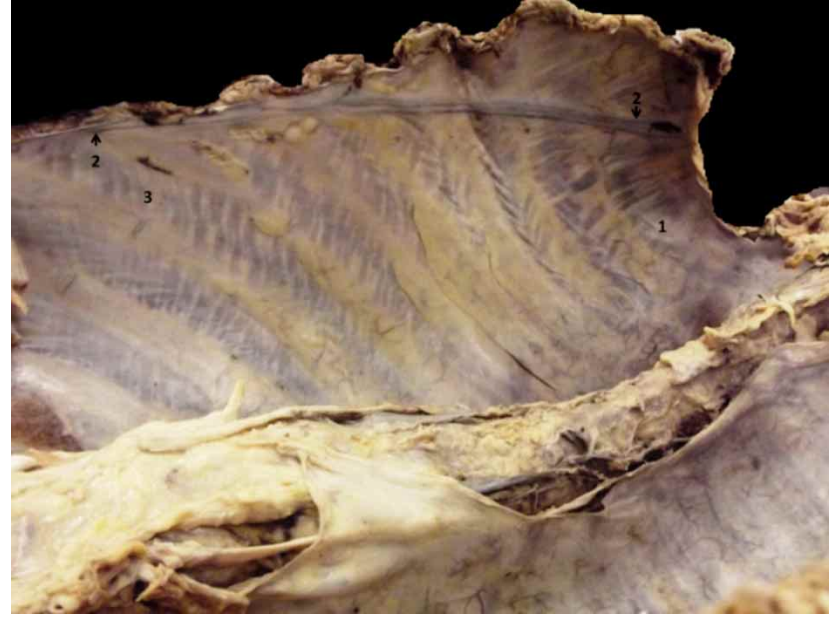

Fig. 1. Internal face of right side of the thoracic wall. 1 Second intercostal space; 2. Lateral costal vessel; 3 . Eighth intercostal space.

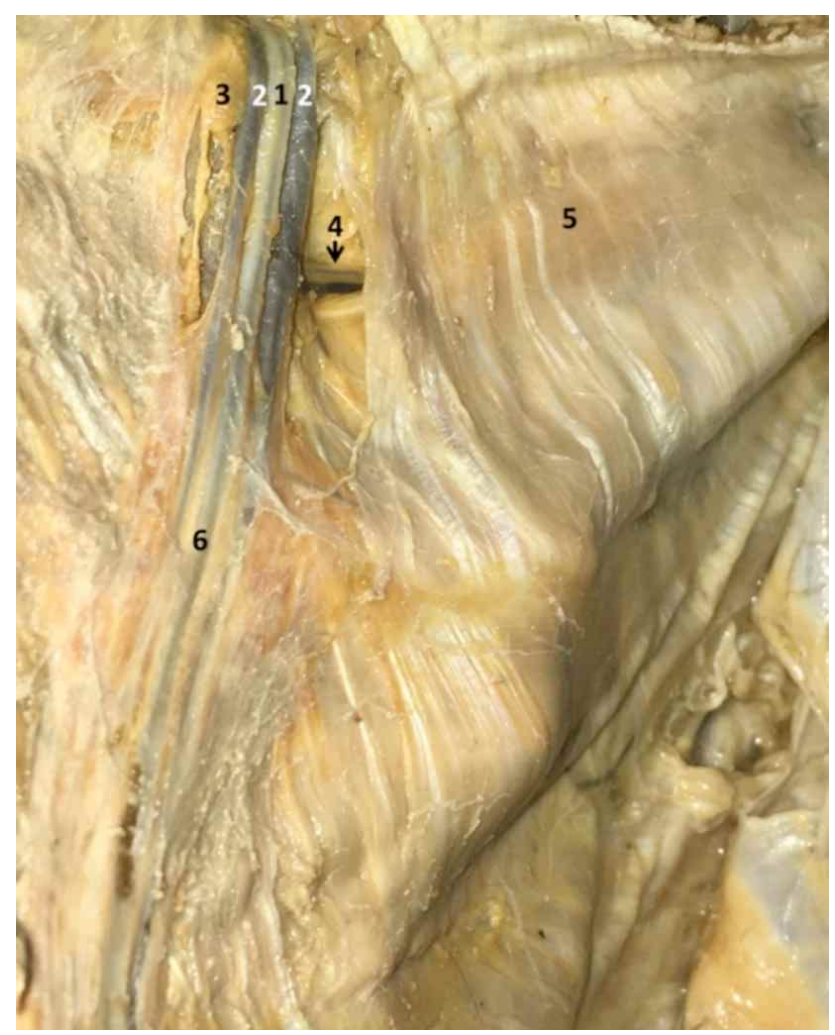

Fig. 2. The right lateral costal vessels with their disposition and relationships in the thoracic wall. 1. Lateral costal branch; 2: Lateral costal veins; 3 . Intercostal lymph node; 4 . Intercostal vessels; 5. Intimate intercostal $M$; 6 . Lateral costal vessels covered by endothoracic fascia.

two lateral costal veins join and form a single vein that drains into the intercostal veins of the eighth intercostal space.

Left lateral costal branch. The left lateral costal branch is distributed over a smaller area than the right branch. As in 
the right counterpart, this branch originates in the internal thoracic artery at $1.5 \mathrm{~cm}$ from its origin. In traverse plane the endothoracic fascia. From its origin, it follows a descending and oblique path toward the anterior at the level

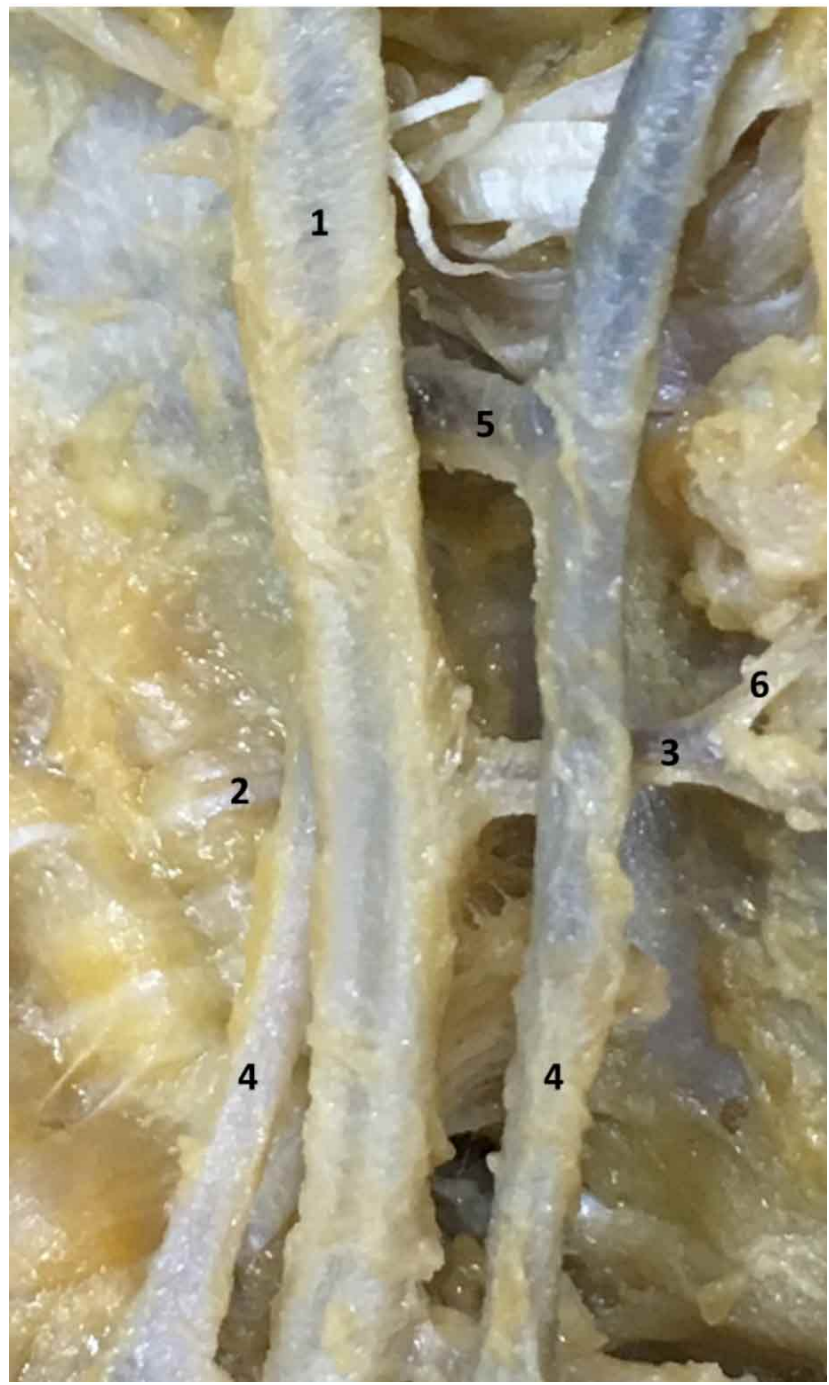

Fig. 3. The left side of the internal face of the thoracic wall. 1 Second intercostal space; 2. Lateral costal vessels; 3 . Sixth intercostal space; 4 . Folded costal parietal pleura. of the medial axillary line, extending to the sixth intercostal space where anastomose with the intercostal arteries of the sixth intercostal space, generating an intermediate longitudinal vascular axis for this vessel in the same manner as observed in the right side. It emits direct branches to the thoracic wall and communicating branches along to the anterior and posterior intercostal arteries (Fig. 4), thus forming part of its arterial circuit. It is $14 \mathrm{~cm}$ long and a caliber of $1.55 \mathrm{~mm}$ at its origin. It is accompanied by two satellite veins that establish anastomosis between them, forming a single vein that communicates with the intercostal veins of the sixth intercostal space.

In all the measurements, the right lateral costal branch was longer and had a larger caliber than the left side, as can be noted in Table I.

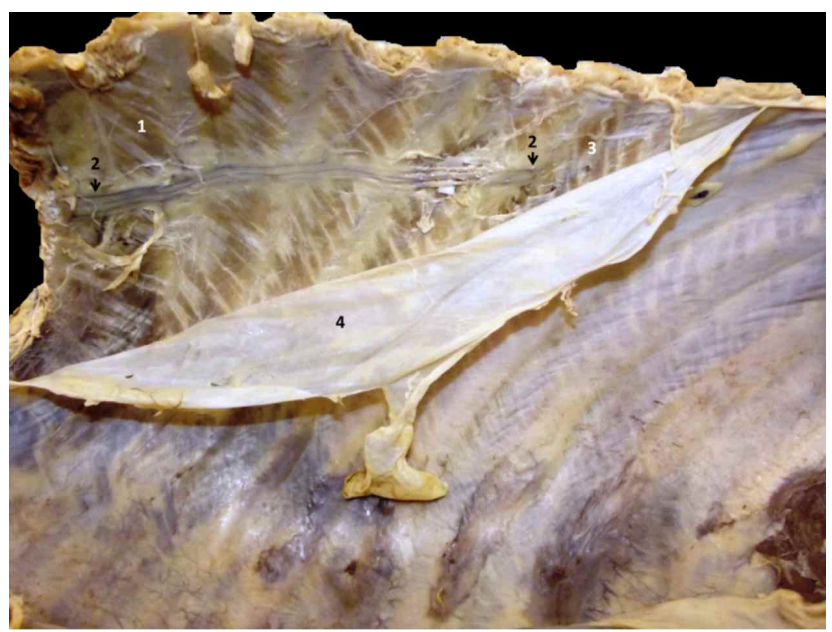

Fig. 4. The left side of the endothoracic fascia was folded back, exposing the anastomosis of the lateral costal vessels between them and with the left side of the intercostal vessels. 1. Lateral costal branch; 2. Communicating branches for the posterior intercostal arteries; 3 Communicating branches for the anterior intercostal arteries; 4. Lateral costal veins; 5 . Anastomosis between lateral costal veins; 6. Muscular branch originating from the communicating branch.

Table I. Measurements of the Internal Thoracic Arteries and the lateral costal branches on both sides are presented.

\begin{tabular}{lcccc}
\hline & B. Costal Lat. $\mathrm{R}^{\circ}$ & A. Thoracic Int. $\mathrm{R}^{\circ}$ & B. Costal Lat. $\mathrm{L}^{\circ}$ & A. Thoracic Int. $\mathrm{L}^{\circ}$ \\
\hline Length & $26 \mathrm{~cm}$ & $17 \mathrm{~cm}$ & $14 \mathrm{~cm}$ & $15.5 \mathrm{~cm}$ \\
Caliber & $1.95 \mathrm{~mm}$ & $4 \mathrm{~mm}$ & $1.55 \mathrm{~mm}$ & $3 \mathrm{~mm}$ \\
Intercostal level & 8 th space & 6 th space & 6 th space & 6 th space \\
Satellite veins & 2 & 2 & 2 & 2 \\
$\mathrm{~N}^{\circ}$ of Anastomosis & 8 & $*$ & 6 & $*$ \\
\hline
\end{tabular}




\section{DISCUSSION}

The lateral costal branch is a variation present in 15-30 $\%$ of populations. There is little information on its possible phylogenetic significance. In contrast to mammals with a circular thorax (primates), in mammals with a major ventrodorsal axis (quadrupeds) the internal intercostal artery runs obliquely after crossing the first rib and emits a branch that runs ventrally in parallel to the sternal border and that supplements the anterior intercostal arteries. The specialization of the upper extremity in prehensile function and the circular expansion of the thorax explain this difference between quadrupeds and primates. Barberini et al. (2004) states that the human lateral costal branch is equivalent to the internal lateral thoracic in quadrupeds, while the anterior branch in quadrupeds is equivalent to the internal thoracic artery in primates. This disposition is explained as an adaptation to the shape of the thorax.

The lateral costal branch is a vessel that follows continues in parallel and laterally to the internal thoracic artery from which it originates. Knowledge of it is relevant for thoracic surgeons (Chaves Chaves \& Sánchez Rojas, 2013). Testut \& Latarjet (1945) describe it as a branch originating from the subclavian artery, citing Fawcett (1914). However, the International Anatomy Terminology currently defines the lateral costal branch as a variant branch of the internal thoracic artery. From a surgical point of view, it is appropriate to keep in mind both arterial origins when dissecting them, the variation considered in this work being bilateral and originating in the internal thoracic arteries.

It is interesting to note that among the first uses of the internal thoracic artery for myocardial revascularization negative clinical results were found attributed to limited blood flow (Singh et al., 1973) owing to inadequate calibers (Grondin et al., 1975) or other causes of reduced blood flow to the heart, like the theft of fluid from a large-caliber collateral branch (Singh \& Sosa, 1981; Nakhjavan et al., 1993). This syndrome of "coronary theft", which affects the arterial flow from the left internal thoracic artery to the interventricular branch of the left coronary artery, has been widely documented and attributed to the presence of a larger collateral branch (Wolfenden \& Newman, 1992; Nakhjavan et al.; Sbarouni et al., 1994; Chavan et al., 1996), the lateral costal branch being one of them (Sbarouni et al.; Hijazi et al., 1996; Guzon et al., 2004; Abdo et al., 2005; Nishi et al., 2012). However, the coronary theft syndrome remains controversial (Guzon et al.). The lateral costal branch has been undescribed in current anatomy or surgical literature (Barberini et al.), therefore, many surgeons are not aware of its existence, despite its prevalence and the possibility of a bilateral presentation. In addition minimally invasive surgical techniques restrict the view of the proximal part of the internal thoracic artery from which the lateral costal branch emerges, the first two centimeters being difficult to access, as described in the literature and in the present work (Chavan et al.).

Angiograph studies have demonstrated the variable presentation of the collateral branches of the internal thoracic artery, pre- and postoperative assessment having been of great help in this study (Singh, 1980). Thus, it is recommended that the internal thoracic artery be viewed specifically in diagnostic coronary angiograms when the use of this artery is considered for myocardial revascularization (Feit et al., 1992). In spite of these recommendations, late investigation has been made of the lateral costal branch in the context of correcting angina symptomatology with embolization by transcatheter (Nakhjavan et al.; Chavan et al.; Abdo et al.) or surgical ligature with or without sternotomy (Hijazi et al.). Only one case is reported where this correction was not possible given that occlusion of the lateral costal branch was accompanied by severe and immediate discomfort in the thoracic wall (Nishi et al.). Without doubt, this reinforces the argument of the responsibility of the lateral costal branch in the coronary theft syndrome. Given its similarity to the internal thoracic artery, the lateral costal branch has been used as a conduit in myocardial revascularization (Hartman et al., 1990; Piazza et al., 1999).

These data affirm that the lateral costal branch is a vessel that should be considered in any preoperative evaluation for thoracic surgery given that it forms part of the circulation of the thoracic wall when it anastomoses with the anterior and posterior intercostal vessels, generating an accessory longitudinal vascular axis that can directly influence coronary theft. As well, our study shows the presence of these veins bilaterally, with a caliber equivalent to $50 \%$ of the caliber of internal thoracic artery from which it originates. To this is added anastomosis with intercostal vessels that span more than half the length of the thoracic wall. Consequently, it is critical that thoracic surgeons are aware of the existence of this anatomical variation and the possible implications that the presence of the lateral costal branch can have in surgical procedures.

As a final reflection, this type of anatomical variation demonstrates the relevance of anatomical knowledge for specialists and surgeons, considering that modern anatomy texts reduce anatomical content to the clinically useful and necessary, which is sufficient for the undergraduate, but is inadequate for the postgraduate and the specialist.

ACKNOWLEDGEMENTS. We are especially grateful to the people who in an act of enormous generosity have donated their body to science, with this noble gesture contribute to the formation of new medical information. 
FARFÁN, C. E.; INZUNZA, H. O. \& ECHEVERRÍA, M. M. Rama costal lateral bilateral (r. costalis lateralis): Una variación anatómica clínicamente relevante. Int. J. Morphol., 35(4):1512-1516, 2017.

RESUMEN: La rama costal lateral es una variación presente en el 15-30 \% de los casos, y sigue paralelo y lateral a la arteria torácica interna, de la cual se origina, siendo su conocimiento relevante para los cirujanos de tórax. Se presenta un hallazgo durante una disección en una actividad práctica docente, en un cadáver de sexo masculino de 62 años. Se accedió al contenido torácico levantando la pared esternocostal, procedimiento que comenzó con disección de la piel y musculatura hasta exponer ambas clavículas, se realizó un corte transversal de éstas en su tercio lateral para posteriormente realizar sección bilateral desde la primera hasta la octava costilla siguiendo la línea axilar anterior. Una vez revertida la pared esternocostal, se seccionaron los pedículos pulmonares, y se retiraron ambos pulmones. Se observó bilateralmente en la pared torácica el trayecto de un paquete vascular a nivel de la línea axilar media paralela a la arteria torácica interna. En el lado derecho se originaba a $2 \mathrm{~cm}$ del trayecto de la arteria torácica interna y se extendía hasta el octavo espacio intercostal con una longitud de $26 \mathrm{~cm}$ y un calibre de $1,95 \mathrm{~mm}$, estableciendo comunicaciones con las arterias intercostales anteriores y posteriores, agotándose en ellas. La rama izquierda se originaba a $1,5 \mathrm{~cm}$ del trayecto iniciado por la arteria torácica interna extendiéndose hasta el sexto espacio intercostal; presentó un calibre de $1,55 \mathrm{~mm}$ y una de longitud de $14 \mathrm{~cm}$, estableciendo comunicaciones con las arterias intercostales anteriores y posteriores, agotándose en ellas. En ambos lados las arterias eran acompañadas por un par de venas satélites. Las arterias costales laterales forman parte de la circulación de la pared torácica, constituyendo un sistema arterial accesorio al de la arteria torácica interna y la aorta. Su conocimiento es relevante en procedimientos invasivos, además de tener un alto valor docente y formativo.

PALABRAS CLAVE: Rama costal lateral; Variación anatómica; Anatomía clínica.

\section{REFERENCES}

Abdo, N.; Curran, P. J.; Kumar, V. \& Tobis, J. M. Coronary steal syndrome with coil embolization of a large LIMA side branch: radionuclide evidence for reversible ischemia. Catheter Cardiovasc. Interv., 66(3):360-3, 2005.

Barberini, F.; Cavallini, A.; Carpino, G.; Correr, S. \& Brunone, F. Lateral costal artery: Accessory thoracic vessel of clinical interest. Clin. Anat., 17(3):21826, 2004.

Cameron, A. A.; Green, G. E.; Brogno, D. A. \& Thornton, J. Internal thoracic artery grafts: 20-year clinical follow-up. J. Am. Coll. Cardiol., 25(1):18892, 1995.

Chavan, A.; Mügge, A.; Hohmann, C.; Amende, I.; Wahlers, T. \& Galanski, M. Recurrent angina pectoris in patients with internal mammary artery to coronary artery bypass: Treatment with coil embolization of unligated side branches. Radiology, 200(2):433-6, 1996.

Chaves Chaves, D. \& Sánchez Rojas, M. Variante anatómica: Arteria torácica anterior. Med. Leg. Costa Rica, 30(1):141-4, 2013.

Feit, A.; Reddy, C. V.; Cowley, C.; Ibrahim, B. \& Zisbrod, Z. Internal mammary artery angiography should be a routine component of diagnostic coronary angiography. Cathet. Cardiovasc. Diagn., 25(2):85-90, 1992.

Fitzgibbon, G. M.; Kafka, H. P.; Leach, A. J.; Keon, W. J.; Hooper, G. D. \& Burton, J. R. Coronary bypass graft fate and patient outcome: angiographic follow-up of 5,065 grafts related to survival and reoperation in 1,388 patients during 25 years. J. Am. Coll. Cardiol., 2(3):616-26, 1996.

Green, G. E.; Stertzer, S. H.; Gordon, R. B: \& Tice, D. A. Anastomosis of the internal mammary artery to the distal left anterior descending coronary artery. Circulation, 41(5 Suppl.):II79-85, 1970.

Grondin, C. M.; Lespérance, J.; Bourassa, M. G. \& Campeau, L. Coronary artery grafting with the saphenous vein or internal mammary artery. Comparison of late results in two consecutive series of patients. Ann. Thorac. Surg., 20(6):605-18, 1975.

Guzon, O. J.; Klatte, K.; Moyer, A.; Khoukaz, S. \& Kern, M. J. Fallacy of thoracic side-branch steal from the internal mammary artery: analysis of left internal mammary artery coronary flow during thoracic side-branch occlusion with pharmacologic and exercise-induced hyperemia. Catheter Cardiovasc. Interv., 61(1):20-8, 2004.

Hartman, A. R.; Mawulawde, K. I.; Dervan, J. P. \& Anagnostopoulos, C. E. Myocardial revascularization with the lateral costal artery. Ann. Thorac. Surg., 49(5):816-8, 1990

Hijazi, A.; Mazhar, R.; Odeh, S. \& Qunnaby, I. Coronary steal through anomalous internal mammary artery graft. Treated by ligation without sternotomy. Tex. Heart Inst. J., 23(3):226-8, 1996.

Locker, C.; Schaff, H. V.; Dearani, J. A.; Joyce, L. D.; Park, S. J.; Burkhart, H. M.; Suri, R. M.; Greason, K. L.; Stulak, J. M.; Li, Z. \& Daly, R. C. Multiple arterial grafts improve late survival of patients undergoing coronary artery bypass graft surgery: analysis of 8622 patients with multivessel disease. Circulation, 126(9):1023-30, 2012.

Lytle, B. W.; Blackstone, E. H.; Sabik, J. F.; Houghtaling, P.; Loop, F. D. \& Cosgrove, D. M. The effect of bilateral internal thoracic artery grafting on survival during 20 postoperative years. Ann. Thorac. Surg., 78(6):2005-14, 2004.

Maddock, S.; Tang, G.; Aronow, W. \& Malekan, R. Total Arterial Revascularization in Coronary Artery Bypass Grafting Surgery. In Artery Bypass. New York, InTech, 2013.

Nakhjavan, F. K.; Koolpe, H. A.; Bruss, J.; Najmi, M. \& Radke, T. Transcatheter coil occlusion for treatment of left internal mammary-anterior descending artery steal phenomenon. Catheter. Cardiovasc. Diagn., 28(4):347-50, 1993.

Nishi, H.; Sakaguchi, T.; Miyagawa, S.; Yoshikawa, Y.; Fukushima, S.; Sumitsuji, S. \& Sawa, Y. Failed depiction of patent bypass graft due to presence of large lateral costal artery. Ann. Thorac. Cardiovasc. Surg., 18(3):275-7, 2012.

Piazza, L.; Renzulli, A.; Scardone, M.; Ismeno, G. \& Cotrufo, M. Myocardial revascularization with arterial conduits. The use of lateral costal artery. $J$. Cardiovasc. Surg., 40(3):385-6, 1999.

Popovic, B.; Voillot, D.; Maureira, P.; Vanhuyse, F.; Agrinier, N.; Aliot, E.; Folliguet, T. \& Villemot, J. P. Bilateral internal mammary artery bypass grafting: long-term clinical benefits in a series of 1000 patients. Heart, 99(12):854-9, 2013.

Sbarouni, E.; Corr, L. \& Fenech, A. Microcoil embolization of large intercostal branches of internal mammary artery grafts. Cathet. Cardiovasc. Diagn., 31(4):334-6, 1994.

Singh, H.; Flemma, R. J.; Tector, A. J.; Lepley, D. Jr. \& Walker, J. A. Direct myocardial revascularization. Determinants in the choice of vein graft or internal mammary artery. Arch. Surg., 107(5):699-703, 1973.

Singh, R. N. \& Sosa, J. A. Internal mammary artery--coronary artery anastomosis. Influence of the side branches on surgical result. J. Thorac. Cardiovasc. Surg., 82(6):909-14, 1981.

Singh, R. N. Internal mammary arteriography: a new catheter technique by right brachial approach. Cathet. Cardiovasc. Diagn., 6(4):439-49, 1980

Testut, L. \& Latarjet, A. Anatomía Humana. Tomo Segundo. Angiología y Sistema Nervioso Central. 8th ed. Barcelona, Salvat Editores S. A., 1945.

Wolfenden, H. D. \& Newman, D. C. Avoidance of steal phenomena by thorough internal mammary artery dissection. J. Thorac. Cardiovasc. Surg., 103(6):1230-1, 1992

\section{Corresponding author:}

Emilio Farfán Cabello M.Sc. Klgo.

Profesor Asistente

Departamento de Anatomía Normal

Facultad de Medicina

Pontificia Universidad Católica de Chile

Libertador Bernardo O’Higgins 340

Edificio Pregrado de Medicina $8^{\circ}$ piso

Santiago - CHILE

Email: efarfan@med.puc.cl

Received:06-09-2017

Accepted:29-09-2017 